\title{
Can the design of space-transport development strategies influence on noise pollution?
}

\author{
Lasmini Ambarwati ${ }^{1 *}$, Amelia K. Indriastuti ${ }^{2}$, Yatnanta P.Devia ${ }^{1}$ and Deputri N.Sari ${ }^{3}$ \\ ${ }^{1}$ Department of Civil Engineering, University of Brawijaya, 65142 Malang, Indonesia \\ ${ }^{2}$ Department of Civil Engineering, Diponegoro University, 50275 Semarang, Indonesia \\ ${ }^{3}$ Alumnus of Department of Civil Engineering, , University of Brawijaya, 65142 Malang, Indonesia
}

\begin{abstract}
The rapid growth of transportation in developing countries brings advantages and disadvantages. One of the disadvantages gives negative impacts, such as traffic jam, which directly decreases a highway performance as well as increases air and noise pollution. A suitable policy has not been formulated to overcome the traffic jam in most highways in big cities. However, traffic demand management regard to noise pollution is required in most cities of developing countries, particularly Surabaya City, as a case study area. This study aims to understand the influence of saturated flow of highway on noise pollution for several types of road corridors. The results reveal that saturated flow of highway has a significant effect on noise pollution. By examining the alternatives of space-transport development strategies, the intention is to reduce noise pollution together with decreasing traffic jam due to decreasing the number of light vehicles. This research proposes the improvement of public transport (PT) by planning a Mass Rapid Transit ((MRT). In addition, a structure of compact zones is designed as urban spatial strategy alternatives. Its substantially reduction is achieved with the design of improvement of PT systems and compact zone. The best option for reducing noise pollution level, the implementation of an integrated space-transport development strategy, is then recommended.
\end{abstract}

\section{Introduction}

Rapid expansion of city areas is occurring world-wide. The phenomenon of urban sprawl has an important role in the build-up of urban areas, influencing living conditions and mobility.

Urban sprawl has been identified in most Indonesian cities. It reflects a pattern of urban development with increasing settlement growth in the suburbs since the beginning of the 20th century. The phenomenon of urban sprawl also occurs in the city of Surabaya as case study area, are characterized by an estimated $38 \%$ of the population lives in the suburbs [1]; most of them commute every day to work in the central urban area.

Surabaya, as a case study area, is the capital city of East Java Province with the second dense population after the state capital of Jakarta. Surabaya has an area of $333,063 \mathrm{~km}^{2}$.

*Corresponding author: lasmi68@yahoo.com; labarwati@ub.ac.id 
Surabaya is divided into five areas namely Central Surabaya, North Surabaya, East Surabaya, South Surabaya, and West Surabaya.

Traffic congestion in the city of Surabaya has strongly increased since the late 1990s; predominantly due to increasing numbers of motorcycles and private cars. Private car $(30 \%)$, motorcycle $(62 \%)$, and other vehicle types ( $8 \%$, mostly minibuses) are the existing transport mode chosen by residents. This situation results in significant increase of time, cost and productivity losses, and an increase in air and noise pollutions. A major consideration for reducing pollution and improving mobility is undertaken by developing strategies for sustainable transportation linked to spatial planning. Such a strategy is expected to change modal split from private vehicles to public transport, to reduce noise from motorized vehicles, and to decrease travel time and distance. Private vehicle is currently a substantial source of noise pollution and traffic congestion in urban areas.

Integrated a road traffic noise model and air pollution model was conducted by employing Geographic Information System (GIS) [2]. The model was developed in order to investigate the existing four urban forms on the Macao Peninsula influence on vehicle transport and street environment. The urban forms in historical areas with narrower roads, complex road networks and a higher density of intersections lead to lower traffic volumes and consequently to lower noise pollution. The Calculation of Road Traffic Noise (CRTN) prediction model was employed to predict noise levels at 28 locations in the City of Amman. The model was successful in predicting noise levels at most of the locations and more accurate predictions for night-time measurements [3].

Some researchers reveal that the mitigatory measures to overcome such type of traffic noise pollution through a design of noise barrier along the road. This effort is useful for motivating people towards the use of public transport system [4]. The light motor vehicles are the main source of noise pollution in the city and have higher correlation coefficient values in generating noise pollution under interrupted traffic flow conditions in urban areas of Indian cities [5].

Previous research on decreasing noise from traffic, has focused insufficiently on understanding change of the number of private vehicles on highway, urban form and land use in the city. Linkage between spatial and transport development strategies in minimizing noise pollution is insufficient due to the fact that the existing efforts only consider on road corridor activities.

The aim of study is to determine the road performance and the degree of noise pollution by improving public transport and reducing the use of private vehicles linked to management of the urban form.

The research results are useful to understand the change of noise level by developing space-transport development strategies and to assess the effects of transport policies addressing to reduce noise.

This paper is organized as follows: Section 2 explains research method. Section 3 explains space-transport development strategies by considering improvement of public transport and design of urban development scenarios. Section 4 identifies the change of modal split for each alternative of space-transport development strategies. Comparison noise level on differences of road corridors is stated in Section 5. Section 6 shows the change of noise level for each alternative. Finally, Section 7 discusses conclusions and recommendations for further analysis. 


\section{Research Method}

The city of Surabaya, a case study area, is the second biggest city in Indonesia, as seen in Fig. 1 . The city has a population of 2,765,908 [1]. The population density of the city was estimated more than 11,000 people per $\mathrm{km}^{2}$ in 2011 . This city has a major problem related to settlement development for its residents. Since the beginning of the 20th century, urban sprawl has been identified in most Indonesian cities. It reflects a pattern of urban development with increasing settlement growth in the suburbs. The phenomenon of urban sprawl occurs in the city of Surabaya, are characterized by an estimated $45 \%$ of built-up area in the central urban areas and $38 \%$ of the population lives in the suburbs [1]; most of them commute every day to work in the central urban area. This extensive growth in economic and residential development has significant consequences for high mobility, as well increasing pollution.

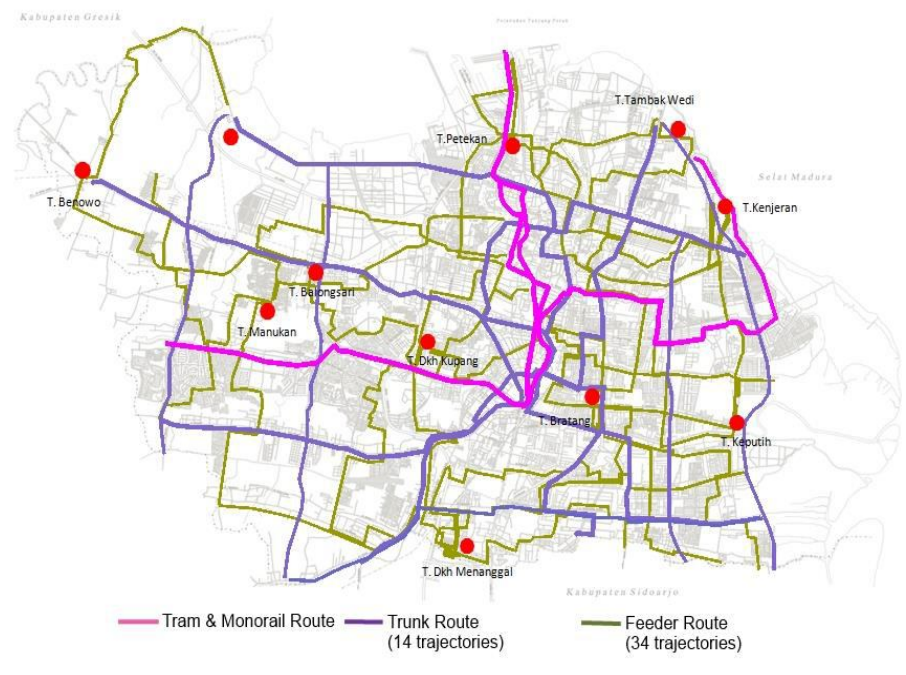

Fig. 1. Study Area, Surabaya City and monorail routes.

The research framework consists of the background condition of public transport system and spatial urban development, further plan of space-transport development. The result is expected to reduce the use of private vehicles and noise pollution, to increase the beneficial received from design of space transport development, as shown in Fig. 2.
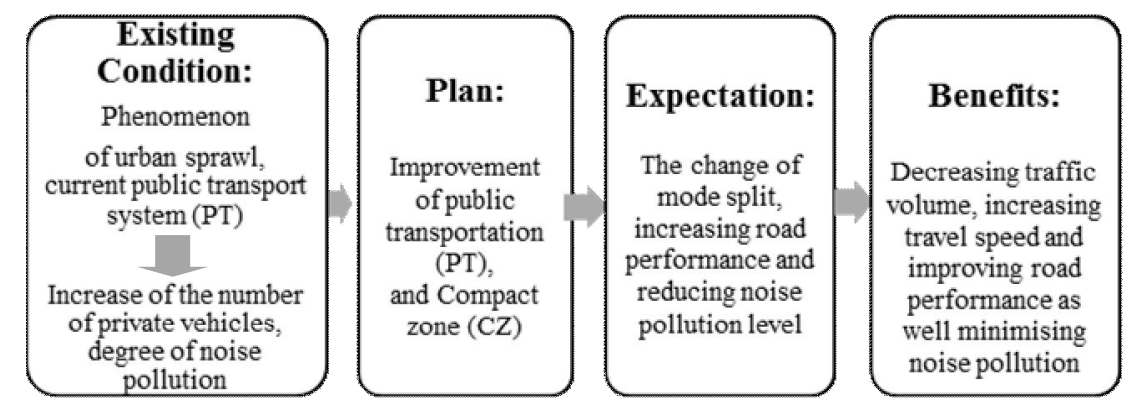

Fig. 2. The research framework. 
This study is empirical research supporting by transport data, collected by an extensive survey. The questionnaire was distributed to 554 respondents spread out over the 163 zones (neighborhoods). The questions were divided into three groups: socio economic background, trip characteristic and transport mode choice, and residents' satisfaction regarding public transport. Other data, i.e. traffic counting, speed study and road geometric inventory were investigated on 31 road-sections of Surabaya City. Traffic volume, speed and road corridors are analyzed to assess noise level. Five alternatives of space-transport development strategies are proposed to analyze the differences of noise levels.

\section{Space-Transport Development Strategies}

A set of simulations, consisting a spatial settlement strategy and a transport system were carried out. The impacts from this set of simulation cases were compared and formed as input for the formulation of strategic options for integrated development of the city. A total of three spatial settlement scenarios and two alternative (public) transport situations are combined into five simulation alternatives (cases). The cases are: (1) Existing (2010) settlement, (2) Settlement 2030 based on a continuation of current trends, (3) Settlement 2030 with the consideration of a so called compact zone in the western part of the city, (4) Situation 2030 with improvement of MRT + LRT, and (5) Situation 2030 currently planned (compact zone)+ PT systems (MRT and LRT).

Five alternatives of space transport development are simulated in order to reduce the large number of private vehicles. Alternatives which promote a modal shift towards public transport and will positively contribute to increased accessibility and minimized noise level.

\subsection{Improvement of Public Transport}

The existing Surabaya public transport network comprises minibus/paratransit, busses and trains. There are 68 available paratransit routes, and 22 bus routes (minibus accommodates 8-12 passengers, while bus has 50-55 seats). Most bus routes use national/provincial roads and toll roads in the middle area of city, other areas are served by paratransit. The paratransit routes have no fixed time schedule or frequency. Bus and paratransit are driven more during the day than the night. The frequency of minibusses and busses are approximately 20-25 vehicles/hours and 5-6 vehicles/hours respectively.

The improvement of the public transport service is regarded as an alternative to reduce the number of private vehicles. Several needed improvements of public transport have been identified. The set up and modeling of those public transport systems, including model calibration based on an extensive survey, have been elaborated in previous study [6].

The Local Government has planned to improve transport infrastructures such as a MRT and LRT system, as explained in Fig. 3. Monorail (MRT) accommodates the passengers in the western and eastern regions. Improvement with this system is expected to increase the public transport passengers. Thus, noise level will reduce because of declining the number of private vehicles and increasing travel speed.

The properties of the proposed MRT and LRT are: a ticket price of approximately $\$ 0.82$, stop spacing of $0.5-2 \mathrm{~km}$, seat capacity of 177 seats for the MRT and 100 seats for the LRT, frequency of 12 vehicles/hour, and an average speed of $55 \mathrm{~km} / \mathrm{h}$ for the MRT and $35 \mathrm{~km} / \mathrm{h}$ for the LRT $[7,8]$. The improvements to public transport are expected to encourage the users of cars and motorcycles to shift their transport mode to the public transport systems. 


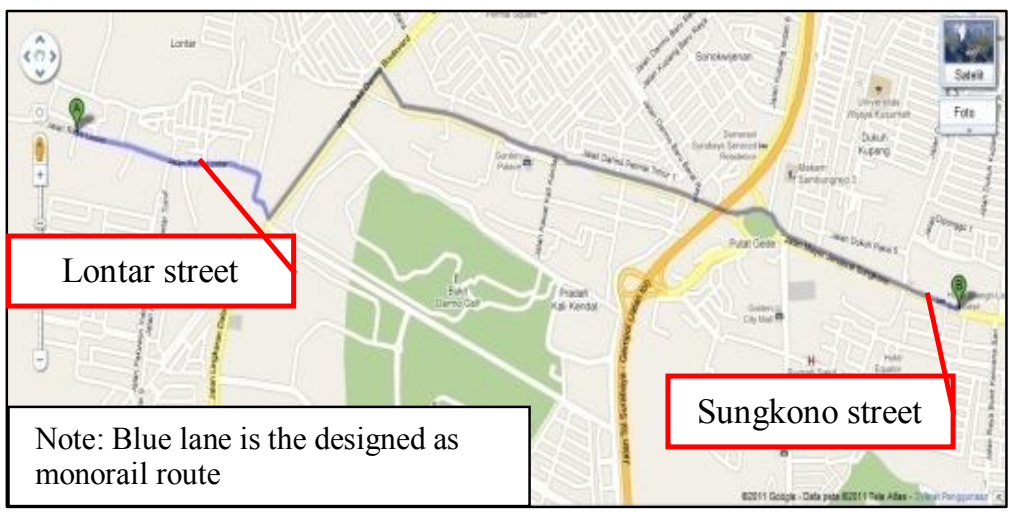

Fig. 3. Monorail (MRT) routes passing from eastern to western side of city, through two road sections with different road corridors.

\subsection{Spatial Development Scenarios}

Simulation of spatial development strategies is based on the existing spatial panning and transport network, the design of a compact zone in particular regions related to the Spatial Masterplan of the city of Surabaya. Three alternative city structures are considered with distinct spatial planning. They are elaborated below.

\subsubsection{Current situation and Current trend}

The current situation 2010 describes the current settlement for the city of Surabaya. The spatial schematization comprises 163 administrative zones ('desas") of Surabaya City; 5 regions are considered (central, north, south, west, and east), as shown in Fig. 4.

The total area of the city is approximately 33,637 hectares, about $65 \%$ of which can be found in the west and east regions. These regions have the built-up area less than $15 \%$, meaning that there is more potential for development in these regions than in other regions of the city.

Settlement development has extended to the outskirts of the urban area, particularly on the western and eastern sides of the city since the 1980s. The 135,000 households live in the suburbs. The highest job density due to new industrial enterprises has developed on some zones of the western regions. These regions create a significant number of jobs for the city, approximately $20 \%$ of total employment. On the other hand, a low population density occurs in the regions, furthermore resulting in a high employment-population ratio. The transport infrastructures in these regions are inadequate, and as a consequence it takes more than 90 min by motorized vehicles and more than $110 \mathrm{~min}$ by PT to reach the city center.

The current trend 2030 comprises the projected development of Surabaya in 2030, based on a continuation of the current situation and implementation of current planned transport interventions; further an annual growth of 5\% GDP and 1\% employment has been adopted over a 20 year period (2010-2030). In this scenario, the population will reach approximately 4.5 million residents, with the lowest population in the western regions. Employment growth is more equally divided over the city with a total number of almost 1.6 million jobs [8]. 


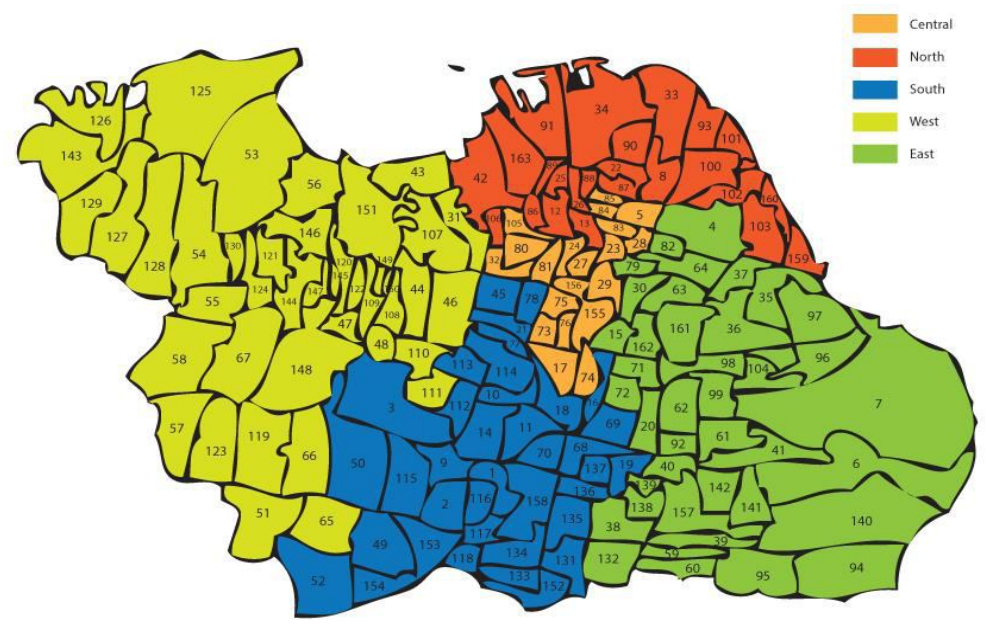

Fig. 4. The "Desa" level and regions of the city of Surabaya.

\subsubsection{Compact zone balanced with distribution employment}

A compact zone was designed at a high density with mixed land-uses and complementary functions such as housing, shopping and offices. The compact zone is considered a strategy to reduce energy use in households and the extent of everyday travel in densely populated area [9]. Based on this study, the compact zone strategy is considered in the Spatial Masterplan of the city of Surabaya. Observation on the distribution of employment and residential density in the city indicates relatively high employment in the western part of the city attracting workers from other parts of the city. In this part, the local government has set up new factory centers, and this has led to a higher employment density in this area of the city. Currently, the residential areas are located away from industrial areas and other business areas [8].

The compact zone strategy in the present analysis has been designed by using a similar overall current trend 2030 with GDP growth 5\% and employment rate of $1 \%$. However for this zone (the western part of the city) the ratio of employment to population increases $3 \%$ from the current trend 2030. The compact zone strategy in the present analysis has been designed in previous research [8].

\section{The Modal Split for Each Alternative}

This section presents the assessment of change of modal split and road performance in order to assess the noise level for each alternative. Five alternatives of space-transport development are simulated in order to reduce the large number of private vehicles. Alternatives which promote a modal shift towards public transport and will positively contribute to increased accessibility and to minimize noise level.

Each alternative has an effect on the change of modal split for each vehicle class. Table 1 presents the results on modal split for different alternative. Improvement of public transport systems are intended to increase the use of public transport in each alternative [8].

The following results in Table 1 can be made:

- The design of combination of MRT and LRT systems (A4) encourages the use of public transport up to $37 \%$. 
- Spatial strategy with the design of a compact zone in the western regions (A3) also does not have an influence on the increase of public transport use either.

- A fifty one percent increase in the use of PT indicates that public transport passengers are more interested in alternative with a design incorporating a space-transport development strategy than other alternatives. This finding means that the alternative of the design of a space-transport development strategy will reduce significantly the load of private motored vehicles and noise level on the road corridors.

Table 1. Modal split for each alternative (\%).

\begin{tabular}{|l|r|r|r|r|r|}
\hline \multirow{4}{*}{ Transport mode } & \multicolumn{3}{|c|}{ Spatial Development Strategies } & \multicolumn{2}{c|}{ Transport Options } \\
\cline { 2 - 6 } & 2010 & \multicolumn{4}{|c|}{2030} \\
\cline { 2 - 6 } & $\begin{array}{c}\text { (A1) } \\
\text { Current } \\
\text { Base }\end{array}$ & $\begin{array}{c}\text { (A2) } \\
\text { Current } \\
\text { trend }\end{array}$ & $\begin{array}{c}\text { (A3) } \\
\text { Compact } \\
\text { zone }\end{array}$ & $\begin{array}{c}\text { (A4) } \\
\text { MRT and } \\
\text { LRT }\end{array}$ & $\begin{array}{c}\text { (A5) } \\
\text { MRT + LRT and } \\
\text { compact zone }\end{array}$ \\
\hline Public transport & 5.82 & 5.62 & 5.66 & 7.72 & 8.45 \\
\hline Motorcycle & 58.73 & 63.39 & 64.3 & 58.7 & 59.34 \\
\hline Car & 34.88 & 30.23 & 29.2 & 28.7 & 27.11 \\
\hline Bicycle & 0.57 & 0.75 & 0.82 & 5 & 5.09 \\
\hline
\end{tabular}

Provision of sufficient PT is necessary to take over from other modes but an adequate urban structure is needed to make a new PT system successful and is expected to minimize noise level.

\section{Comparison Noise Level on Highway Corridor}

The existing traffic flow on two road corridors, i.e. business activities and residential area is analysed to compare noise level. This assessment is to understand the extensive use of motorized vehicles influencing noise level.

Analysis of noise level is based on basic noise level with some corrections for mean speed and the number of heavy vehicles, gradient, pavement surface, condition of noise source to recipient, building condition, and view angle.

The values were analysed using the procedure for determining noise level for motorized vehicles [10]. The basic noise level ((dBA) is based on the assumption for normal traffic flow, no heavy vehicles on the traffic, and average speed $75 \mathrm{~km} / \mathrm{h}$, explained as follows:

$$
L_{10}=42.2+10 \log Q
$$

which $Q$ is traffic volume.

\subsection{The Differences Noise Level in the Existing Condition}

The existing road geometry for two road sections, i.e. Mayjen. Sungkono Street (road corridor as business area) and Lontar Street (as residential areas) are described six-lane two-way and two-lane two-way local highways respectively. The existing road performance in term of degree of saturation (DS) are 1.3 (Mayjen. Sungkono street) and 0.6 (Lontar street). 
The noise level on road corridor as business areas is amounted to $80.881 \mathrm{dBA}$, exceed than the Noise Standard Level (70 dBA). Other road corridor as residential area is estimated of $77.963 \mathrm{dBA}$ which is much greater than the Noise Standard Level (55 dBA). Thus, the values of both road corridors were exceeds the noise threshold stated in the Noise Standard Level. The values mean that traffic flow should be decreased by designing improvement public transport and spatial planning in order to reduce the number of private vehicles and noise level. Table 2 explains the average values of noise level in the existing condition for both road corridors.

Table 2. The Average values of noise level in the existing condition.

\begin{tabular}{|l|l|c|c|c|c|}
\hline \multirow{2}{*}{ Street } & \multirow{2}{*}{ Road corridor } & \multicolumn{3}{|c|}{ Average Value of Noise Pollution } & \multirow{2}{*}{$\begin{array}{c}\text { Average } \\
\text { (dBA) }\end{array}$} \\
\cline { 3 - 5 } & & Morning & Noon & Afternoon & (dBA) \\
\hline $\begin{array}{l}\text { Mayjen. } \\
\text { Sungkono }\end{array}$ & $\begin{array}{l}\text { Business } \\
\text { activities }\end{array}$ & 81.518 & 80.161 & 80.964 & 80.88 \\
\hline Lontar & $\begin{array}{l}\text { Residential } \\
\text { area }\end{array}$ & 78.561 & 77.284 & 77.954 & 77.96 \\
\hline
\end{tabular}

Degrees of saturations are assessed in the morning and noon in order to understand the correlation with noise level for each peak hour and off-peak hour of traffic flow. Fig. 5 and Fig. 6 show the relationship between the degree of traffic saturation with noise level. From the results $\left(\mathrm{R}^{2}\right)$ of fitting the regression linear, it means that degree of saturation of both traffic flow on those road corridors have an effect to the noise level.
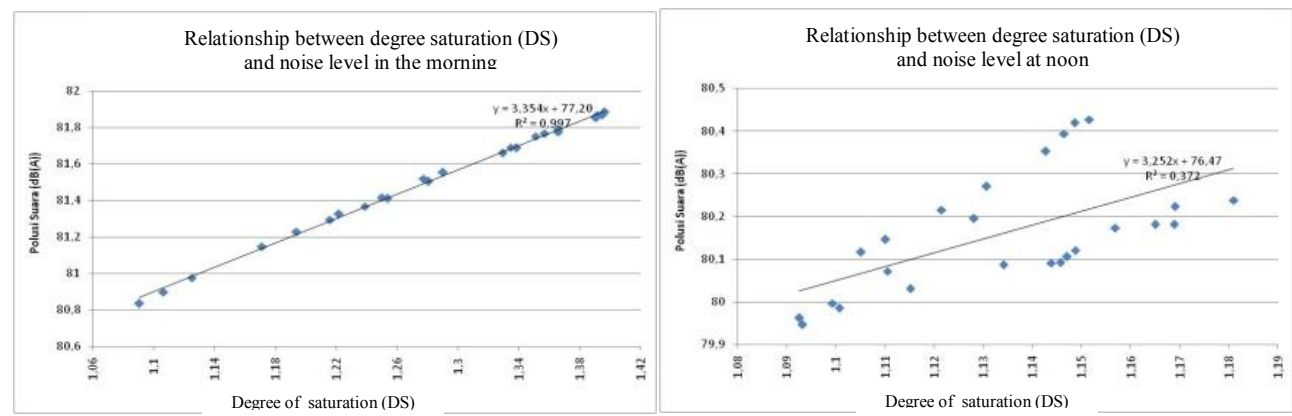

Fig. 5. The relationship between DS and noise level on Mayjen. Sungkono street in the existing condition.
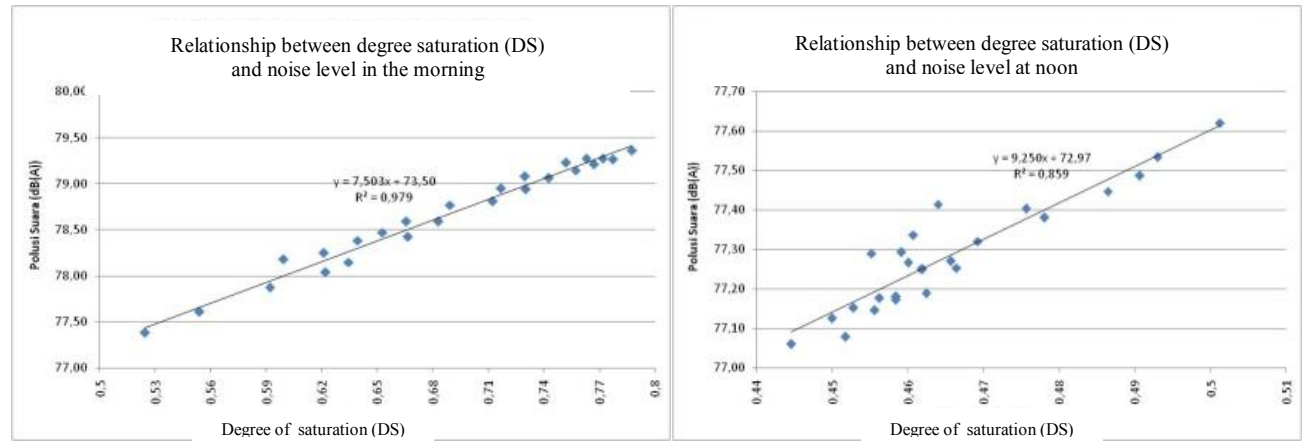

Fig. 6. The relationship between DS and noise level on Lontar street in the existing condition. 


\subsection{The Difference Noise Level by Reducing $10 \%$ of Light Vehicle (LV) and Heavy Vehicle (HV)}

This section explains the reducing $10 \%$ of light vehicle (LV) and heavy vehicle (HV) influencing noise level in both road corridors. Minimizing noise level on both road corridors is expected below the Noise Standard Level and to be accepted by human health.

Table 3 explains the decreasing noise level by reducing the number of LV and HV in traffic flow on both road corridors (business activity and residential area). Table 3 shows that decreasing the number of LV is significantly reducing noise level on both road corridors, estimated $0.5 \%$. The reduction occurs due to the number of light vehicles much greater than decreasing heavy vehicle volume.

Table 3. The change of noise level due to reducing $10 \% \mathrm{LV}$ and HV.

\begin{tabular}{|l|l|c|c|c|c|c|}
\hline \multicolumn{1}{|c|}{ Street } & $\begin{array}{c}\text { Road } \\
\text { corridor }\end{array}$ & $\begin{array}{c}\text { Existing } \\
\text { condition }\end{array}$ & $\begin{array}{c}\text { Reducing } \\
10 \% \mathrm{LV}\end{array}$ & $\begin{array}{c}\text { Decreasing } \\
(\%)\end{array}$ & $\begin{array}{c}\text { Reducing } \\
10 \% \mathrm{HV}\end{array}$ & $\begin{array}{c}\text { Decreasing } \\
(\%)\end{array}$ \\
\hline $\begin{array}{l}\text { Mayjen. } \\
\text { Sungkono }\end{array}$ & $\begin{array}{l}\text { Business } \\
\text { activities }\end{array}$ & 80.881 & 80.448 & 0.54 & 80.858 & 0.03 \\
\hline Lontar & $\begin{array}{l}\text { Residential } \\
\text { area }\end{array}$ & 77.963 & 77.556 & 0.52 & 77.936 & 0.04 \\
\hline
\end{tabular}

\section{The Change of Noise Level for Each Alternative}

Concerning the mode choice, the combination of improved PT systems (i.e. MRT + LRT) and compact zone (A5) encourages more passengers to use public transport. This alternative is expected to decrease noise level. The results of noise level in each alternative are presented in Table 4.

Table 4. The noise level for all cases (dBA).

\begin{tabular}{|l|l|c|c|c|c|c|}
\hline \multirow{2}{*}{ Street } & \multirow{2}{*}{ Road corridor } & \multicolumn{3}{|c|}{2010} & \multicolumn{4}{|c|}{2030} \\
\cline { 3 - 7 } & & \multicolumn{3}{|c|}{ Spatial scenarios } & \multicolumn{2}{c|}{ PT system options } \\
\cline { 3 - 7 } & & (A2) & \multicolumn{1}{c|}{ (A3) } & (A4) & (A5) \\
\hline $\begin{array}{l}\text { Mayjen. } \\
\text { Sungkono }\end{array}$ & $\begin{array}{l}\text { Business } \\
\text { activities }\end{array}$ & 80.881 & 87.3 & 82.04 & 74.9 & 74.12 \\
\hline Lontar & $\begin{array}{l}\text { Residential } \\
\text { area }\end{array}$ & 77.963 & 84.15 & 79.08 & 72.19 & 71.45 \\
\hline
\end{tabular}

The following results in Table 4 can be made:

- The design of combination of MRT and LRT systems (A4) has a significantly effect on noise level

- Spatial strategy with the design of a compact zone in the western regions (A3) does not have an influence on reducing noise level.

- A significant change of noise level is identified by a design incorporating a spacetransport development strategy (A5). Thus, noise level on road corridor as business activities is approximately the National Noise Level Standard.

- Briefly, noise level is under level stated in the National Noise Level Standard, in which the reduction of light and heavy vehicle volume is approximately $14 \%$ of traffic volume on Mayjen. Sungkono Street (trade/business area) and 30\% on Lontar Street (residential area) respectively. 


\section{Conclusions and Recommendations}

This study demonstrated an integrated approach, comprised of interventions in urban structure and public transport, is necessary to address the mobility and noise level problems in fast growing urban areas and the associated effects of urban sprawl. An important factor in urban transport planning is an assessment of noise level. The change of noise level was analysed for five alternatives.

The alternative with improved PT systems such as MRT and LRT combined with design of compact zone (A5) was characterized by the smallest noise level, while the spatial development strategy with compact zone (A3) demonstrated an insignificant decrease of noise level.

The compact zone strategy does not provide better noise level. Other strategy in urban planning should be designed, such as examining closest job housing, in order to assess the effect on reducing noise level due to expectation of decreasing travel length and the number of use of private vehicles. Integration of spatial-transport strategies as well as an environmental assessment should provide more sophisticated and long-term advantages, especially improvement of environmental quality when designing improvements of public transport systems related to housing planning.

\section{Acknowledgement}

The authors thank to Libertina Widyamurti Ambari for her valuable assistance in writing the manuscript of draft paper.

\section{References}

1. Statistic Bureau of Surabaya, The Figures of Surabaya City (in Indonesian) (2010)

2. U.W. Tang, Z.S. Wang, Environ. Model. Softw. 22, 1750-1764 (2007)

3. A. Jamrah, A. Al-Omari, R. Sharabi, Environ. Monit. Assess. 120, 499-525 (2006)

4. R.K. Mishra, M. Parida, S. Rangnekar, Int. J. Environ. Sci. Technol. 7 (4), 737-750 (2010)

5. S. Agarwal, B.L. Swami, Environ. Monit. Assess. 172, 113-120 (2011)

6. L. Ambarwati, R. Verhaeghe, A.J. Pel, B. van Arem, WIT Trans. Ecol. Environ. 138, 653-668 (2014b)

7. Department of Transport of Surabaya City, Surabaya MRT: Surabaya Mass Rapid Transportation (SMART). Technical Report. Surabaya, Indonesia (2013)

8. L. Ambarwati, R. Verhaeghe, A.J. Pel, B. van Arem, Transp. Res. D Trans. Environ. 44, 134-146 (2016)

9. E. Holden, I.T. Norland, Urban Stud. 42, 2145-2166 (2005)

10. C.S. Papacostas, P.D. Prevedouros, Transportation Engineering Planning. Hawai (1993) 